\title{
Novel modality for management of mandibular fracture by 3D non-locking miniplate: A case report
}

\author{
Shivam Agarwal ${ }^{1 *}$, Prashansa Sharma ${ }^{2}$, Sanjeev Kumar ${ }^{3}$, Gagan Khare ${ }^{4}$ \\ ${ }^{1,2}$ Senior Lecturer, ${ }^{3}$ Professor, and Head, ${ }^{4}$ Professor, ${ }^{1,3,4}$ Dept. of Oral and Maxillofacial Surgery, ${ }^{2}$ Dept. of Periodontology, ITS Dental \\ College, Muradnagar Ghaziabad, Uttar Pradesh, India
}

*Corresponding Author: Shivam Agarwal

Email: shivamagarwal@its.edu.in

\begin{abstract}
Mandible fractures have a vital place within the injuries of the other bones of the oral and maxillofacial system and Trauma is the common etiological factor that involves break in continuity of bone. Mandible fractures management involves cosmetic and functional aspects such as chewing, speaking, and swallowing. Mandible anterior fractures are most common form of mandible fractures. They involve the breach in continuity of mandible leading to masticatory and occlusal problems due to the biomechanical forces. The purpose of this case report is to discuss the management of mandible anterior fracture by 3D non locking miniplate.
\end{abstract}

Keywords: Miniplate, Breach, Trauma, Mandible fracture.

\section{Introduction}

Immobilization is the first requirement in healing of mandible fracture and the purpose of all therapies for fractures is the restoration of the original form and function. Failure to achieve these conditions of healing results in the complications like infection wound dehiscence etc. Osteosynthesis implies functionally stable internal fixation of bone fractures, which allows the early recovery of function. Champy suggested that when the plates are placed along the ideal line of osteosynthesis they give maximum stability and proper osteosynthesis. ${ }^{1}$ Open reduction and internal fixation (ORIF) with miniplates and screws has proven to be the most effective method, associated with minimal morbidity, early mobilization and return to work. Rigid systems have been replaced by more functionally oriented systems and the term "semi rigid" has gained more importance. Rigid fixation can produce three dimensional stability of the fracture site, promoting primary fracture healing. This 3D plate with quadra angular design formed by joining two miniplates with interconnection crossbars was developed by Framand in the year 1992. 3D titanium plates and screws were then gradually developed, and reported by Dupoirieux. ${ }^{2,3}$ The stability is gained over defined surface area in three dimensions due to its configuration, not by thickness or length and it offers good resistance against torsional forces. ${ }^{4,5}$ We report the case of mandibular anterior fracture which was managed by $3 \mathrm{D}$ titanium non locking miniplate. For fixation of a fracture segment, one has to consider many things such as size, number of fixation devices, their location ease of adaptation and fixation biomechanical stability, surgical approach and amount of soft tissue disruption necessary to expose the fracture and place the fixation devices. ${ }^{6-8}$

\section{Case Report}

A 30 year old patient reported to the department of oral and maxillofacial surgery with the chief complaint of pain in lower front tooth region since one day. Patient gave a history of road traffic accident one day back and an emergency treatment was given at nearby hospital. The patient was conscious with GCS score of 15 (E4V5M6). Patient gave a history of bleeding from the mouth immediately after trauma but no history of unconsciousness $\&$ bleeding from the ear and nose as well as no intraoral and extra oral laceration. On intraoral examination a step was felt at canine region which was tender on palpation and hematoma was seen in the floor of the mouth. There were no other injuries elsewhere in the body; all the teeth were clinically present. Based on the history and clinical features, a provisional diagnosis of mandible fracture involving the parasymphysis was made.

Following immobilization, for confirmation of the provisional diagnosis, an OPG was advised. The radiograph revealed a well-defined radiolucent line running from distal to lateral incisor and downward to the inferior border of mandible. (Fig. 1) But on correlating with the type of injury and the extra oral clinical findings, the presence of a mandibular left parasymphysis fracture was ruled out. Exploratory surgery was explained to the patient and informed consent was taken. After all the basic hematological investigations and pre-anesthetic checkup, patient was taken for open reduction and internal fixation under general anesthesia. Erich's arch bar fixation was achieved under local anesthesia preoperatively. Under proper aseptic condition patient was painted with $2 \%$ providone iodine intraorally and extraorally and draping was done after that $2 \%$ lignocaine $(1: 80,000)$ was infiltrated at surgical site.
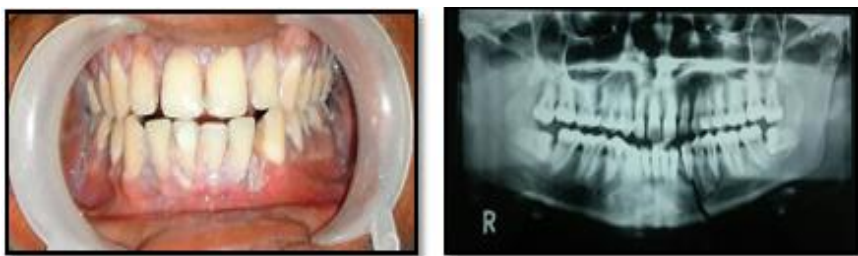

Fig.1: Preoperative occlusal view and OPG 
An intraoral mandibular vestibular degloving incision was used and curvilinear (vestibular) incision $5 \mathrm{~mm}$ apical to the mucogingival junction was given. The mentalis muscle was exposed and incised perpendicular and deep to the bone, leaving a flap of muscle attached to bone for closure. A full thickness mucoperiosteal flap was raised carefully keeping the mental neurovascular bundle intact and expose the fracture site. (Fig. 2) After obtaining adequate exposure of the fractured segments, the segments were manipulated and satisfactorily reduced. After reduction of the fractured segments, temporary intermaxillary fixation was done to achieve the satisfactory occlusion and fixation of the fractured segment was achieved by $2 \mathrm{~mm} 3-\mathrm{D}$ non locking titanium miniplate. (Fig. 3) The area was irrigated with Betadine \& saline and adequate hemostasis was achieved. The deeper layers of the wound were closed using 3-0 Vicryl and mucosal layer was closed with 3-0 silk. (Fig. 4) Intermaxillary fixation was released and an adhesive pressure bandage was given extraorally. Radiograph was taken postoperatively to check the adequacy of reduction and fixation. (Fig. 5) After discharge the patient was recalled on the $1^{\text {st }}$ week, $1^{\text {st }}$ month, $3^{\text {rd }}$ month follow up respectively. (Fig. 6) However patient was also instructed to report for any complaint post operatively any time. On each appointment apart from the routine examination and wound care, occurrence of complications was checked.

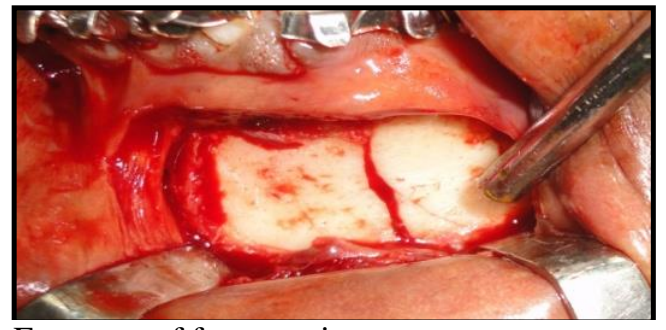

Fig. 2: Exposure of fracture site

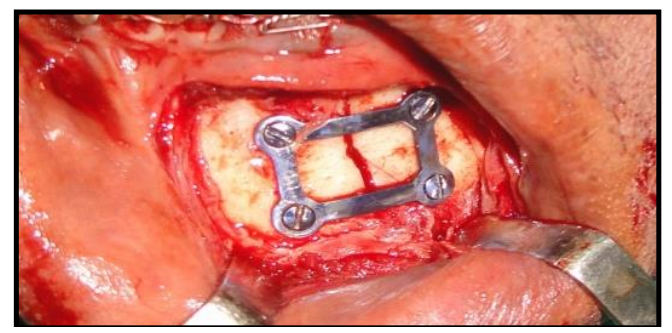

Fig. 3: Fixation of 3-D non locking miniplates

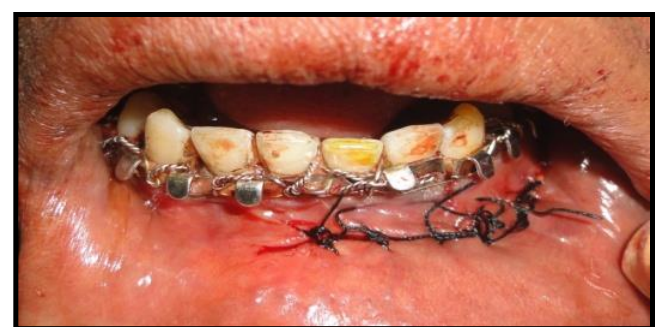

Fig. 4: Closure done with 3-0 mersilk

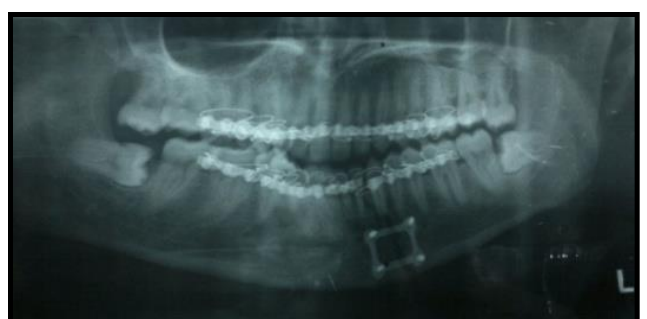

Fig. 5: Postoperative OPG

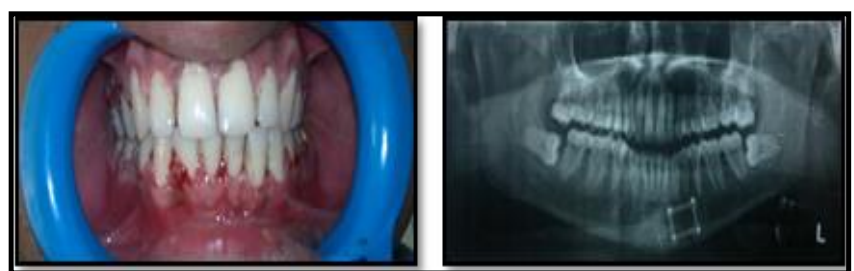

Fig. 6: Post operative occlusion \& OPG after 3 months

\section{Discussion}

Mandible fractures are the commonest fracture on the face usually caused by accidents and other possible etiologies may be interpersonal violence, falls, sports injuries etc. ${ }^{5}$ The newly introduced 3D plating system provides definite advantages over conventional miniplates. The $3 \mathrm{D}$ plating system uses fewer plates and screws as compared to conventional miniplates to stabilize the bone fragments. Thus it uses lesser foreign material, reduces the operation time and overall cost of the treatment as described by Zix J, Lieger O and lizuka T(2007) and Farmand M (1995). ${ }^{6,9,10}$ The need of osteosynthesis for mandibular fracture is to minimize the movement between the two fractured segments to promote the sound healing. This healing process can be deterred by the masticatory loads which can cause movements in between the fractured segments. Simplified adaptation is the one of the advantage for the $3 \mathrm{D}$ titanium miniplate without any displacement to the fracture with this there is simultaneous adaption of both the superior and inferior border of the mandible. As Champy et al described the ideal line of osteosynthesis in which the system of semi rigid fixation with screws and miniplates were introduced but in this case we are using 3D titanium non locking miniplates for the management of mandibular anterior fracture ${ }^{1,9,10}$ Because of their miniature size it can be easily placed and time saving alternative to conventional miniplate. The horizontal cross bar of the 3D titanium miniplate is placed perpendicular to the fracture line and the vertical cross bar is placed parallel to the fracture line. The less foreign material and maximum stability can be produced by this $3 \mathrm{D}$ titanium miniplate due to its closed quadrangular geometric configuration. ${ }^{7}$ As it also helps in osteosynthesis because less surgical exposure is done with less implant material is used for the management of mandibular fracture and less amount of periosteal stripping is done in $3 \mathrm{D}$ titanium miniplate as compared with the conventional miniplates. According to the recent survey 20$25 \%$ of the surgeons do not prefer to use this 3D titanium miniplate because of its disadvantages like difficult to placed in oblique fracture, fracture near mental foramen and 
areas with limited access. It is exorbitant then other conventional miniplates. ${ }^{11,12}$ In this case, it was seen that $3 \mathrm{D}$ titanium miniplate was effective in the treatment of mandibular fractures and overall complication rates were less. In the symphysis and parasymphysis region, 3D plating system uses less foreign material, as only one plate and four screws are used as compared to two plates and eight screws in case of conventional miniplates using champy's principle. ${ }^{1}$ This also reduces the operating time and overall cost of the treatment.

Thus 3D plate can be used as an alternative to conventional miniplates. The system is reliable and effective treatment modality for mandibular fractures as compared to traditional miniplates. Further, the use of 3D plating system in various procedures of maxillofacial region needs to be explored.

\section{Conclusion}

We conclude that the 3D titanium miniplate are a superior method for the management of mandibular fracture as it provide better stability and approximation radiographically and helps in osteosynthesis and can restore normal form and function easily. Intermaxillary fixation is required for 1 week as comparison with conventional miniplate. This 3D plate is made up of titanium which is biocompatible material and it is a desirable mode of treatment of mandibular fracture.

\section{Source of funding}

None.

\section{Conflicts of interest}

The authors declare they have no potential conflicts of interest regarding this article.

\section{References}

1. Champy M, Pape HD, Gerlach KL, Lodde VP. The Strasbourg miniplate osteosynthesis. Vol. II. Kruger, Eberhard; Schilli, Wilfried; Worthington, Phillip. Oral and Maxillofacial Traumatology. Quintessence publishing Co In.USA.1981;19. 41.

2. Jain M, Manjunth. Comparison of 3- Dimensional and standard miniplate fixation in the management of mandibular fracture. $J$ Oral Maxillofac Surg 2010;68:1568-1657.

3. Farmand M. The 3-D plating fixation in maxillofacial surgery. J Oral Maxillofac Surg 1993;51:166-16.

4. Alpert B, Seligson D. Removal of asymptomatic bone plates used for orthognathic surgery and facial fractures. J Oral Maxillofac Surg 1996;54:618-21.

5. Cawood JI Small plate osteosynthesis of mandibular fractures. Br J Oral Maxillofac Surg 1985:77-91.

6. Zix Juergen, Lieger Olivier, Lizuka Tateyuki. Use of straight and curved 3- dimensional titanium miiplates for fracture fixation at the mandibular angle. JOMS 2007;65:1758-63.

7. Parmar S Babu et al. 3-Dimensional miniplate rigid fixation in fracture mandible. J Maxillofac Oral Surg 2007;6:14-6.

8. Kim Kyung Y, Ho-Hwan and Cheul- Seung. Tissue response to titanium plates: A transmitted electron Microscopy Study. $J$ Oral Maxillofac Surg 1997;55:322-6.

9. Farmand M. The 3-D plate fixation of fractures and osteotomies. Facial Plast Surg 1993;3:39-56.

10. Farmand M and L Dupoirieux. The value of 3-Dimensional miniplates in maxillofacial surgery. Rev Stomatoi Chir Maxillofac 1992;93(6):353-7.

11. Schliephake H, Lehmann H. Ultrastructural findings in soft tissues adjacent to titanium plates used in jaw fracture treatment. Int J Oral Maxillofac Surg 1993;22:20-5.

12. Jain M. And K. Sankar. Management of mandibular fractures using 3 dimensional looking and standard titanium miniplatesA comparative preliminary report of 10 cases. $J$ Craniomaxillofac Surg 2012;6:475-8.

How to cite this article: Agarwal S, Sharma P, Kumar S, Khare G. Novel modality for management of mandibular fracture by 3D non-locking miniplate: A case report. $J$ Dent Specialities 2019;7(2):140-3. 